\title{
Borges, Babel y las Matemáticas
}

No soy el primer autor de la narración

"La Biblioteca de Babel...".1

Desde el dramático momento en que Zenón de Elea se mordió la lengua para escupírsela al tirano Nearcos, la humanidad lo ha execrado por su conmovedora defensa de las doctrinas de Parménides. ${ }^{2} \mathrm{La}$ parádoxa sobre el concepto de la infinidad con que Zenón defendió los argumentos de Parménides pesó sobre toda la filosofía de Occidente hasta el siglo XIX. Y ahora en nuestro tiempo Borges ha vuelto a usar el enigma de la infinidad aprovechando todas las reverberaciones de los argumentos de Zenón tal como se repiten en la historia de la teo!ogía y la filosofía. Cuando Zenón afirmó que

No existe esa cosa llamada espacio; si la hubiera estatía en algo, porque todo lo que es, está en algo, y lo que está en algo está en un espacio. Así, este espacio estaría en un espacio, y así hasta lo infinito... ${ }^{3}$

inventó literalmente, una disposición hacia el infinito retroceso ante la cual todos sus herederos tendrán que humillarse: un prodigioso recelo. Los teólogos medievales, por ejemplo, estaban obligados a aceptar la exposición zenoniana, porque, como hace notar Al-Ghazali, su credo de que todo efecto tiene una causa, los forzaba -en virtud del infinito retroceso- - a negar todo lo que existe, a menos de que invocasen un Dios no causal de quien emanasen todas las cosas y que a la vez

1. Ficciones, Emece, Bucnos Aires, 1956. Esta nota aparece en el prólogo. Todas las citas de "La Biblioteca de Babel" son de esta edición.

2 Diógenes Laercio, Vitłe Pbilosophorum, Ed. H. S. Long, Oxford, 1964, IX, 27: Plato, Parmenides, Ed. J. Burnett, Oxford, 1967, 128C.

3 Simplicio, Pbys., 562, 3D. Greek Philosopbers, Vol, I, 90-a, Ed. C. J. De Vogel, Leiden, 1957. 
hubiera sido no-causado por su no-causalidad. ${ }^{4}$ Esta es la teoría que Borges maneja en "La Biblioteca de Babel":

Para localizar el libro $A$, consultar previamente un libro $B$ que indique el sitio de $A$; para localizar el libro $B$, consultar previamente un libro $C$, y así hasta lo infinito...5

El resultado de tales reconciliaciones teopáticas con la parádoxa ha sido una abundancia irreverente de refutaciones y conciliaciones con el incongruente aunque común propósito de hacer concordar los disonan. tes lenguajes de los monistas griegos y los monoteístas cristianos. Borges aprovecha este tema con la inagotable precisión de un mecanimo automático, unas veces en forma explícita y otras en contextos velados por paráleipsits como hace en "la esfera de Pascal" o en "Los avatares de la tortuga". Sin embargo, es prácticamente imposible tratar de desenmarañar o separar las diversas posturas metafísicas que asume Borges, y para comprender las desfiguraciones con que se complica tal propósito basta con un examen somero de los textos escolásticos en que errcontramos esos mismos temas ineluctablemente repetidos. Quizá por esta razón la crítica actual dedica sus más intensas búsquedas a descifrar el significado del Aleph, ${ }^{6}$ el Zahir, la infinidad y otros símbolos del mismo género. Son estos símbolos los que colman la cornucopia del crítico estructuralista porque con ellos, como sucede con la siempre omnipresente Bibiloteca de Babel, es imposible crear o caer en nuevos absurdos, ya que no hay ni un solo misterio referente al mito de la infinidad que no haya estado, desde los tiempos antiguos, inextricablemente entretejido con nuestra teología, nuestro lenguaje y nuestra política. Quizá sea Borges el único que nos dé la respuesta apropiada: "Hablar es incurrir en tautologías" 7 Pero no es necesario que lo imitemos en una similar venganza si no es para aclarar que Borges está manipulando un concepto que se extiende a través de todos los sistemas filosóficos. Borges es, como veremos, mucho más un historiador que un mistagogo.

* Al-Ghazali, Tabãfut al-Faläsifah, Prob. V. Trans. Simon van den Bergh, London, 1969.

5 Ficciones, 92-93.

- En matemáticas, el Aleph $\chi$ denota la cardinalidad de un conjunto calculable. La palabra "cardinalidad" expresa lo mismo para los conjuntos infinitos (colecciones de elementos infinitamente numerosos) que las palabras "número de elementos" denotan para los conjuntos finitos. El Aleph es el más infinitesimal conjunto infinito. Es decir, entre los dos más famosos cuentos de Borges, "La Biblioteca de Babel" y "El Aleph" existe una estrecha relación matemática.

7 Ficciones, 94. 
Fue un matemático del siglo XIX, E. E. Kummer, el primero que concibió un fascinante método para ilustrar la inconmensurable distancia entre lo finito y lo infinito. Su plan era construir un edificio utópico llamado la Biblioteca Universal con el fin de probar la inimaginibilidad de un infinito número de libros $-o$ de cualquiera otra cosa - asumiendo un número finito de libros que fuera, relativaments, menor, pero, así y todo, inconcebible. La Biblioteca de Kummer resultó tan apropiada para representar, tanto la insondable distancia entre lo divino y lo humano como para expresar el concepto de lo infinito, que Borges en vez de considerarla alegóricamente, se limitó a proveer el equivalente de una interpolación literaria.

Por ejemplo, todos los libros en la Biblioteca de Kummer contienen los mismos símbolos:

Mil símbolos diferentes para las consonantes, vocales, números dígitos, signos de puntuación, etc., así como el espacio; esta será la materia prima para la impresión de libros, y se puede definir como libro cualquier distribución, - con repeticiones-- de estos símbolos entre, por ejemplo, un millón de espacios disponibles en papel. 8

Borges recurre a una analogía similar para definir la ley fundamen. tal de la Biblioteca de Babel, cuando su misterioso bibliotecario descubre que:

...todos los libros, por diversos que sean, constan de elementos iguales: el espacio, el punto, la coma, las veintidós letras del alfabeto. ${ }^{9}$

y como resultado define como libro cualquier distribución de esos 25 signos ortográficos entre lo que resulta ser 1312000 espacios disponi. bles en papel.

En la Biblioteca Universal de Kummer no puede haber dos libros idénticos, -ni siquiera en un solo espacio,- para que pueda ser finita. Tiene que decir, por lo tanto:

\footnotetext{
8 Abraham A. Fraenkel, Einleitung in die Mengonlebre, 2a edición, Berlín, 1923, pp. 4-5.

${ }^{9}$ Ficciones, 89. La Biblioteca de Babel consta de $25^{1,312,000}$ volúmenes, o sea 25 subido a la potencia de un millón, trescientos doce mil, una cantidad verdaderamente astronómica. La Biblioteca de Kummer tendría 100 1,000,000 volúmenes. Para comprender la magnitud de este número basta comprender que $10^{100}$ (diez subido a la 100 potencia) debe ser representado por un diez seguido de cien ceros.
} 
Todos los libros se guardan en la Biblioteca Universal, la cual contiene un número finito de libros diferentes. ${ }^{10}$ (Itálicas nuestras)

El genial bibliotecario inventado por Borges se expresa en términos muy parecidos, y Borges mismo subraya sus palabras:

No bay, en la vasta biblioteca, dos libros idénticos."

$\mathrm{Y}$ en seguida añade:

... 1a Biblioteca es total $\mathrm{y} .$. sus anaqueles registran todas las posibles combinaciones de los veintitantos símbolos ortográficos (número, aunque vastísimo, no infinito) o sea todo lo que es dable expresar: en todos los idiomas. Todo: la historia minuciosa del porvenir, las autobiografías de los ángeles, el catálogo fiel de la Biblioteca, miles y miles de catálogos falsos, la demostra. ción de la falacia de esos catálogos, la demostración de la falacia del catálogo verdadero, el evangelio gnóstico de Basílides, el comentario de ese evangelio, la relación verídica de su muerte, la versión de cada libro a todas las lenguas, las interpolaciones de cada libro en todos los libros. ${ }^{12}$

A la recíproca, la Biblioteca de Kummer posee:

... todos los libros concebibles; dado que cada libro contiene cierta distribución de los símbolos, y como el número posible de combinaciones es un número finito, nuestro conjunto contiene una cantidad finita de libros diferentes. Allí se halla todas las obras religiosas y filosóficas del pasado y el futuro, todos los dramas $\mathrm{y}$ todas las historias, todas las cosas que podrían ser descubiertas o que serán descubiertas, ... todos los catálogos imaginables, todos los artículos de periódico, todas las participaciones de matr: monio... ${ }^{13}$

También esta Biblioteca es interminable:

10 Fraenkel, 4.

11 Ficciones, 89.

12 Ficciones, 89-90.

18 Fraenkel, 5. 
Porque aunque estuviera impresa en el más delgado de los papeles, en los más diminutos caracteres, el universo - desde la tierra hasta la estrella más lejana, - abarcaría solamente una pequeña parte de uno de los conjuntos finitos de los libros de la Biblioteca."

Por último, en un esfuerzo por reconciliar el conflicto entre los que creen que la Biblioteca de Babel es interminable y la aparente verdad de que el número de volúmenes aunque extraordinariamente alto, tiene un límite, el bibliotecario borgiano introduce el concepto de "período":

...La Biblioteca es limitada y periódica. Si un eterno viajero la atravesara en cualquier dirección, comprobaría al cabo de los siglos que los mismos volúmenes se repiten en el mismo desorden (que, repetido, sería un orden: el Orden)..$^{15}$

Es decir, cuando el viajero ha alcanzado el más alejado ámbito de la Biblioteca de Babel va a descubrit que ésta se halla duplicada en otra Biblioteca donde se repiten los libros de la primera. Esto indica solamente el segundo período, el principio de la segunda Biblioteca, porque más allá de esa hay otra, y después otra, y otra, y así hasta lo infinito. En consecuencia, todas y cada una de las Bibliotecas de Babel, como el espacio de Zenón, están encerradas o incluidas una dentro de la otra. $\mathrm{Y}$ todas estas Bibliotecas combinadas se guardan en una vasta arquitectura que en el caso de Kummer se llama la Biblioteca Universai y en el de Borges la Biblioteca Total. Esta Biblioteca Total, cuya existencia "comprobaría al cabo de los siglos" el eterno viajero, puede ser concebida solamente a través de la complicada noción del "conjunto calculable", esto es, un conjunto que contiene igualmente tantos elementos como el que contiene todos los números naturales. Tales conjuntos infinitos se llaman calculables -o contables- porque sus elementos pueden contarse por medio de los números naturales, $0,1,2$, etc., hasta lo infinito: como ejemplo podríamos escoger el conjunto de todos los números pares. Pero, por extraño que parezca, en la aritmética de lo infinito, el conjunto de los números pares tiene igualmente tantos elementos como el conjunto de todos los números naturales el cual incluye tanto los números pares como los números primos. En este caso ni es el total de todos los números naturales mayor que cualquiera

14 Fraenkel, 5. Borges usa la idea del papel "infinitamente delgado" en la nota a Ietizia Alvarez de Toledo (Ficciones, 95) en la que habla de un número infinito de hojas "infinitamente delgadas."

15 Ficciones, 95. 
de sus partes ni se implica que todos los conjuntos infinitos sean del mismo tamaño; pueden sumarse y restarse de la misma manera que los números naturales. Así podemos decir que la Biblioteca Total evocada por el viajero eterno tiene un calculable número de libros en sus estan. tes. $Y$ también podemos afirmar y probar que cualquiera que sea el libro que alguien seleccione en la Biblioteca de Babel, la Biblioteca Total contiene un número infinito de libros exactamente idénticos. Sin embargo cada conjunto infinito de libros idénticos que corresponde a cada libro particular en Babel tiene el mismo número de elementos (cardinalidad) que el conjunto de todos los libros guardados en la Biblioteca Universal. El número de libros se denomina simplemente el Aleph. Y es así como Kummer anticipó la ancha y soberbia diferencia entre la omnisciente Biblioteca de Babel y la Biblioteca Universal:

Si suponemos que hay un infinito número de cuerpos celestiales donde viven seres inteligentes que escriben libros, podríamos llegar a la conclusión de que libros idénticos, con el mismo autor, casa editorial, y aún las mismas erratas, van a ser publicados en ese infinito número de estrellas; porque todos los libros, por lo menos uno por cada estrella, están archivados en la Biblioteca Universal, la cual contiene un número finito sólo de diferentes libros. ${ }^{16}$

Aunque en el número 59 de Sur Borges haya afirmado que Kurd Lasswitz fue el primer expositor de la Biblioteca Total, puede notarse que la Biblioteca de Babel sigue de cerca el texto que Abraham Fraenkel atribuye principalmente a E. E. Kummer. Naturalmente si Borges hubiera querido estudiar la teoría de los conjuntos en las primeras décadas de este siglo, no hubiera podido hacerlo sino a través del Mengenlebre de Fraenkel. ${ }^{17} \mathrm{Y}$ teniendo en cuenta el seductor atractivo del misterio de lo infinito, no es de sorprender que sea un primordial objeto de kátbexis y que haya influido profundamente en las especulacionss cosmogónicas de hombres tan diversos como Parménides, Einstein $y$ Borges. Un simple esquema de como este fenómeno se repite en la narrativa es suficiente base para una comprensión metafórica de la ma.

16 Fraenkel, 5.

17 Fraenkel se refiere a las conferencias universitarias de Kummer en la misma nota en que se habla de la novela científica de Lasswitz, Traumkristalle. Fl libro de Fraenkel es perfectamente accesible en la edición inglesa de 1953 (NorthHolland Publishing Company, Amsterdam). Otra posible fuente puede haber sido el libro de Hausdorff, de 1914. 
nera en que complementa a Zenón y a la Biblioteca Universal. Parménides, por ejemplo, creyó que el universo es inamovible, inviolado:

Finito en todos sus costados, como la masa de una bien redondeada esfera, igualmente balanceado desde el centro en todas las direcciones. ${ }^{18}$

mientras que Einsten compara nuestro universo a una superficie esférica cuyo principal hechizo

está en aceptar el hecho de que el universo es finito y al mismo tiempo ilimitado. ${ }^{19}$

Por su parte la Biblioteca de Babel es inamovible y limitada, una curiosa amalgama de las características ya citadas, que Borges subraya:

La Biblioteca es una esferd cuya centro cabal es cualquier hexá. gono, cuya circunferencia es inaccesible. ${ }^{20}$

La referencia de Borges a los que creen que el hexágono es una "forma necesaria" de la intuición espacial es, claro está, una crítica enderezada a Kant. Pero de hecho el universo de Borges es einsteniano en cuanto a que los hexágonos no se admiten como formas necesarias del espacio y en cuanto a que cualquier hexágono puede ser considerado el centro del universo. Siguiendo a Zenón es fácil notar que mantener. que cualquier hexágono es el centro del universo equivale a decir que el universo no tiene un centro. ${ }^{21}$ Esta es la tesis que, en forma organizada y coherente, desarrolla Richard Bosley. ${ }^{22}$ Mantiene Bosley quo los antiguos griegos, después de inventar un vocabulario con palabras como "Uno" y "Unidad", se pasaron varios siglos tratando de dilucidar y hacer comprensibles sus creaciones. Inexplicablemente, los Apologistas y los doctores de la Iglesia, asumiendo que los griegos eran los de-

18 Parmenides, Fragmento 8. Die Fragmente der Vorsokraliker, Ed. Hermann Diels, Berlin, 1922.

19 Einstein, Alberto, Uber die sperielle und die allgemeine Relativitatstbeorie, Braunschweig, 1922, sec. 31.

20 Ficciones, 86.

21 Debe tenerse en cuenta que no es el volumen de la esfera sino su superficie lo que es análogo al espacio finito del universo, en consecuencia, cualquier punto de la superficie puede ser denominado el centro.

2.2 Bosley, Richard, "Existence and Purported Reference", Mind, Vol. LXXVII, 1968 , pp. 84-95. La misma tesis se desarrolla en el libro en preparación titulado, Five Concepts in Anitent and Medieval Philosophy. 
positarios de toda sabiduría, trataron de establecer este nuevo lenguaje como la única norma aceptable para hablar de Dios. En consecuencia, la filosofía griega, exaltada por la religión, pasó a contaminarlo todo mientras se movía en una especie de inmunidad demagógica. No puede negarse que Borges parece encontrarla en todas partes como si todo in que él toca lograra convertirse en una pesadilla zenoniana o quizás en otro obediente tema en una variación infinita.

Fue Xenófanes el primero que atacó a Homero por su bestial presentación de los dioses y quien, en consecuencia, estableció los cimientos de la filosofía perménica y de todos los innumerables futuros ensayos de reconciliación entre la cosmogonía griega y la cristiana. Quizás a Borges le parece sugerente $-\mathrm{o}$ tal vez alucinante- notar cómo tan piadosa misión habría de culminar en un aparente desastre y acaso su percepción de nuestra presente ruina cultural le lleva a insinuar que la filosofía griega y la teología cristiana son, para decirlo simplemente, tal para cual, y en justa retribución la humanidad se merece la búsqueda angustiosa e inescapable de lo infinito.

University of Pittsburgh

PEDRo V. AMARAL 